УДК: 797.12.015

DOI https://doi.org/10.26661/2663-5925-2021-3-11

\title{
ОСОБЛИВОСТІ СПЕЦІАЛЬНОЇ ТЕХНІЧНОЇ ПІДГОТОВКИ МЕТАЛЬНИКІВ СПИСУ НА ЕТАПІ СПЕЦІАЛІЗОВАНОЇ ПІДГОТОВКИ
}

\author{
Клопов Р. В. \\ доктор педагогічних наук, професор \\ Запорізький національний університет \\ вул. Жуковського, 66, Запоріжжя, Украӥна \\ orcid.org/0000-0001-9036-4331 \\ clopov-r@ukr.net
}

\author{
Шапочка П. О. \\ студентка II курсу магістратури \\ факультету фізичного виховання здоров'я та туризму, \\ Запорізький національний університет \\ вул. Жуковського, 66, Запоріжжя, Украӥна \\ shapochka.p@gmail.com
}

\begin{abstract}
Ключові слова: техніка метання, технічна підготовка, тренувальна програма, особливості, педагогічний експеримент, рівень підготовленості.
\end{abstract}

У статті визначено та проаналізовано вдосконалення рівня спеціальної технічної підготовленості метальників спису на етапі спеціалізованої підготовки, виявлені специфічні особливості технічної підготовки та підвищення рівня спеціальної технічної підготовленості метальників спису на етапі спеціалізованої підготовки. Кінцевою метою етапу спеціалізованої підготовки $є$ збереження здоров'я спортсмена, вдосконалення техніки метання спису, набуття змагального досвіду для виходу у дорослий спорт і успішної реалізації потенціалу у ньому. Отже, для цього було проаналізована науково-методична, спеціальна література та проведений педагогічний експеримент. До контингенту, що брав участь у педагогічному експерименті, увійшли четверо дівчат та четверо юнаків. На початку та наприкінці педагогічного експерименту було проведено контрольні тестування спеціальної технічної підготовленості на секторі для метання спису. Основним показником результативності був результат у метанні спису, але до уваги бралися й інші показники, такі як: кут вильоту снаряду, кількість вдалих спроб, відстань до лінії після гальмування, темпоритмовий характер техніки та послідовність включення ланок тіла спортсмена. Разом із цим були виявлені типові помилки під час виконання метання спису. Було використано відеозйомку для біомеханічного аналізу техніки метання спису. Розроблена експериментальна та обгрунтована тренувальна програма, за якою проводилось дослідження. Вона мала вдосконалити рівень спеціальної технічної підготовленості метальників спису на етапі спеціалізованої підготовки та поліпшити показники техніки метання спису. Тренувальна програма розвитку технічної підготовленості повинна спиратися на річний план-графік тренувань та індивідуально поставлені завдання для кожного спортсмена. Методами математичної статистики було доведено, що після впровадження розробленої нами експериментальної програми спеціальної технічної підготовленості статистично значуще підвищився рівень вищезазначеної підготовленості. Результати контрольного тестування наприкінці педагогічного експерименту показали покращення результату в середньому на 7,82 $4,34 \%$, а також поліпшення в деяких окремих біомеханічних параметрах техніки метання спису. 


\title{
PARTICULARITIES OF SPECIAL TECHNICAL PRACTICE OF JAVELIN THROWERS AT THE STAGE OF SPECIALIZED TRAINING
}

\author{
Klopov R. V. \\ Doctor of Pedagogical Sciences, Professor \\ Zaporizhzhya National University \\ Zhukovskogo str., 66, Zaporizhzhya, Ukraine \\ orcid.org/0000-0001-9036-4331 \\ clopov-r@ukr.net \\ Shapochka P. O. \\ 2nd-year Master Student \\ Faculty of Physical Education, Health and Tourism \\ Zaporizhzhya National University \\ Zhukovskogo str., 66, Zaporizhzhya, Ukraine \\ shapochka.p@gmail.com
}

Key words: throwing technique, technical training, training program, features, pedagogical experiment, level of preparation.
The article identifies and analyzes the improvement of the level of special technical readiness of spear throwers at the stage of specialized training, identifies specific features of technical training and increases the level of special technical readiness of spear throwers at the stage of specialized training. The ultimate goal of the specialized training phase is to preserve the athlete's health, improve the technique of javelin throwing, gain competitive experience to enter adult sports and successfully realize their potential. For this purpose, scientific and methodological, special literature was analyzed and a pedagogical experiment was conducted. The contingent that took part in the pedagogical experiment included four girls and four boys. At the beginning and end of the pedagogical experiment, control tests of special technical readiness were conducted in the sector for throwing spears. The main indicator of effectiveness was the result in javelin throwing, but other indicators were taken into account, such as the angle of the projectile, the number of successful attempts, the distance to the line after braking, the temporitum nature of the technique and the sequence of body parts. At the same time, typical spear-throwing errors were identified. Video recording was used for biomechanical analysis of spear throwing techniques. An experimental and substantiated training program was developed, according to which the research was conducted. It was to improve the level of special technical training of spear throwers at the stage of specialized training and improve the performance of spear throwing techniques. The training program for the development of technical readiness should be based on the annual training schedule and individually set tasks for each athlete. It was proved by the methods of mathematical statistics that after the implementation of the experimental program of special technical preparedness developed by us, the level of the above-mentioned preparedness increased statistically significantly. The results of control testing at the end of the pedagogical experiment showed an improvement of the result by an average of $7.82 \pm 4.34 \%$, as well as an improvement in some individual biomechanical parameters of the technique of javelin throwing. 
Постановка проблеми. Сучасний етап розвитку світової легкої атлетики характеризується загостренням конкуренції на найбільших змаганнях. Об'єм та інтенсивність навантаження у підготовці легкоатлетів досягли критичних величин. Але подальший зріст обмежується біологічними можливостями організму. Також сьогодні присутня боротьба 3 допінгом у спорті, яка так чи інакше вирівнює спортсменів та дає доброчесно перемогти на змаганнях. Тож у цих умовах, коли подальший розвиток результатів все менше пов'язують зі збільшенням об'єму тренувального навантаження, на змаганнях перемагає той, хто має більш раціональну та стабільну техніку метання спису, яка дозволяє метальнику реалізуватися найкраще серед інших $[1 ; 2 ; 3]$.

У більшості випадків весь процес багаторічної підготовки метальників спису часто не забезпечує якісного вдосконалення підготовленості, а разом із цим зростання спортивного результату. Основна частина представників цього виду легкої атлетики досягає більш низьких результатів у порівняні з майстерністю обраних, при цьому прикладаючи більше зусиль та часу. Також найбільший відплив спортсменів припадає на вік 16-17 років, коли низькі результати не забезпечують умови для продовження тренування, а саме навчальний процес у вищому закладі або поява травмувань. Тому актуальним стає пошук нових шляхів організації навчально-тренувального процесу на етапі спортивної спеціалізації, які будуть забезпечувати покращення спортивного результату та безпечності тренувань для молодого організму, що зумовлять продовження тренувального процесу та виходу спортсмена на високий рівень. Слід також брати до уваги фізіологічні чинники, що впливають на цей процес.

Тож метою нашого дослідження було виявлення особливостей спеціальної технічної підготовки та підвищення рівня технічної підготовленості метальників спису на етапі спеціалізованої підготовки.

Мета, завдання та методи дослідження. Мета роботи - виявлення специфічних особливостей технічної підготовки та підвищення рівня спеціальної технічної підготовленості метальників спису на етапі спеціалізованої підготовки.

Для досягнення мети необхідно вирішити такі завдання: провести аналіз науково-методичної й навчально-методичної літератури $з$ проблеми дослідження; оцінити рівень технічної підготовки у метальників спису 16-18 років; розробити експериментальну програму розвитку спеціальної технічної підготовленості легкоатлетів 16-18 років, що займаються метанням спису на етапі спеціалізованої підготовки; експериментально перевірити тренувальну програму з розвитку технічної під- готовленості легкоатлетів 16-18 років, що займаються метанням спису на етапі спеціалізованої підготовки.

Під час цієї програми були використані такі методи: теоретичний аналіз й узагальнення науково-методичної та спеціальної літератури; педагогічні методи (педагогічне тестування техніки метання спису, педагогічний експеримент); інструментальний метод - відеозйомка; методи математичної статистики: (середне арифметичне, середне квадратичне відхилення, критерій Вілкоксону, коефіцієнт асиметрії, вибірковий ексцес).

Експериментальна програма спрямована на вдосконалення спеціальної технічної підготовленості метальників спису на етапі спеціалізованої підготовки та базується на експериментальній побудові тренувального процесу, що був розроблений та впроваджений нами у період 3 листопада 2020 року по січень 2021 року.

У дослідженні брали участь 8 метальників спису групи спеціалізованої підготовки 1-го року навчання.

Виклад основного матеріалу. Проаналізувавши літературні джерела [4-7], можна зробити висновок щодо специфічних особливостей технічної підготовки метальників спису на етапі спеціалізованої підготовки. Безперечно, слід звертати увагу на фізіологічний стан та розвиток організму спортсмена. Розвиток технічної підготовленості пов'язаний із розвитком мобільності та гнучкості, а отже, з підвищеним ризиком травмуванням. Необхідно поступово розвивати ці рухові можливості. Оскільки метання спису - це складнокоординаційна вправа, іiї слід опановувати відокремленими частинами, а потім з'єднувати в більші структури. Хоча існує класичне виконання техніки метання спису, тренеру все одно потрібно виходити 3 індивідуальних можливостей окремого спортсмена.

Засоби, які використовуються для вдосконалення технічної підготовленості, повинні відповідати певним критеріям відповідності рухової діï. Тренувальна програма розвитку технічної підготовленості повинна спиратися на річний план-графік тренувань та індивідуально поставлені завдання для кожного спортсмена.

На думку багатьох авторів щодо техніки метання спису [8-11], рух правої ноги повинен бути спрямований на: збереження швидкості просування метальника вперед в бік кидка; прискорення загального центру маси метальника вверх-вперед, щоб ще до торкання опори лівою ногою тіло метальника та снаряд вже рухалися в напрямку вильоту; приведення метальника в положення «натягнутого лука». У свою чергу, ліва нога повинна: створити стійкість системи «метальник-снаряд»; забезпечити ефективне гальмування горизонтальної 
швидкості нижньої частини тіла метальника; забезпечити послідовну роботу м'язів тулуба, плечового поясу метальника та руки, що метає; збільшити шлях докладання сили до снаряду.

Отже, в нашій роботі ми досліджували вплив запропонованої програми щодо вдосконалення спортивної техніки в метанні спису на етапі спеціалізованої підготовки серед учнів спортивної школи. Варто зазначити, що всі метальники в даній групі виконують метання саме правою рукою. Тому наступні описи будуть стосуватися праворуких метальників.

Для аналізу техніки метання спису учнів у групі були обрані найбільш значущі елементи, що можна було виміряти за допомогою наявного обладнання. Ці елементи послужили предметом порівняння характеру руху учнів групи спеціалізованої підготовки 1-го року навчання метальників, а саме: результат у метрах, кут вильоту снаряду, відстань до лінії після гальмування, кількість вдалих спроб, характер ритму, послідовність включення в роботу ланок тіла.

За даними [12], кут зльоту становить від 30 до $36^{\circ}$, хоча, як правило, він стає меншим, чим вище швидкість зльоту. Для орієнтування ми порахувати середній кут вильоту та проаналізували мінімальний й максимальний кути, які показали найсильніші метальниці спису. Тож середній кут вильоту дорівнює $35,1 \pm 3,1^{\circ}$, мінімальний $-32^{\circ}$, максимальний $-42^{\circ}$ [9]. Ми привели до єдиного коефіцієнта всі параметри відносно найвищого результату в кожному 3 них (від 1 до 0). Таким чином ми бачимо кореляцію цих параметрів у кожного спортсмена та можемо виявити, які параметри впливають на результат. Результати, представлені на рис. 1, свідчать про те, що більшість спортсменів (юнаки - далі юн, дівчата - далі дів) використовують забагато місця після гальмування, тим самим «з’їдають» свій результат. Для прорахунку цієї відстані були пораховані плитки на відеозйомці, довжина яких становить 0,5 м. Це пов'язано 3 непостійним й неравномірним темпоритмом під час розбігу. Також ми виявили, що більшість учнів виконує замало вдалих спроб, що також свідчить про те, що ще не напрацьований ритм розбігу. Нераціональний кут вильоту в багатьох учнів свідчить про відсутність чіткого контролю снаряду під час його випуску. За експертною думкою тренера та кваліфікованих старших спортсменів, під час проведення біомеханічного аналізу були виявлені такі типові помилки: згинання коліна лівої ноги після постановки стопи та «засідання» на ліву ногу; одночасний рух правої руки та постановки лівої ноги; згинання ліктя правої руки під час «захвату» снаряду; метання «через» поперек, а не «через» груди; різке зниження швидкості під час кидкових кроків.

На основі аналізу науково-методичної літератури [13-16] були виявлені основні положення, на які треба звернути увагу під час створення тренувальної програми: моделювання змагальної результативності та рівня технічної підготовленості; адекватність тре-

$$
\multimap \mathrm{A}(\text { дів }) \multimap \mathrm{B}(\text { дів }) \multimap \mathrm{C}(\text { дів }) \multimap \mathrm{D}(\text { дів }) \multimap \mathrm{E}(\text { юн }) \multimap \mathrm{F}(\text { юн }) \multimap \mathrm{G}(\text { юн }) \multimap \mathrm{H}(\text { юн })
$$

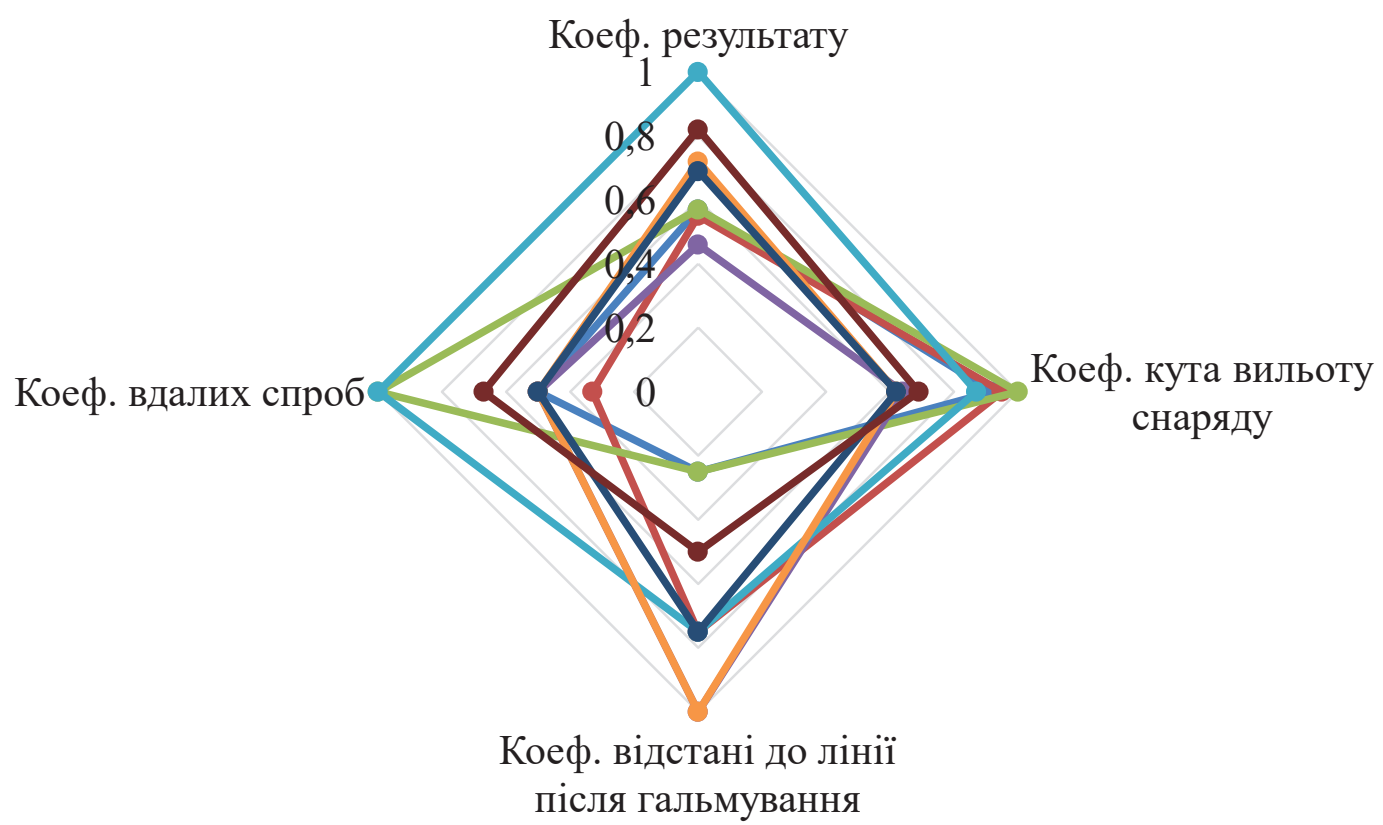

Рис. 1 Біомеханічні параметри метальників спису на початку педагогічного експерименту 
нувальних засобів біомеханічній структурі метання спису; корекція тренувального впливу у відповідності з індивідуальними особливостями метальників.

Ураховуючи вищезгадані положення та наявну програму ДЮСШ, було запропоновано таку тренувальну програму для вирішення типових помилок. Ці вправи виконувалися блоками поступово в кожному мікроциклі 2 рази на тиждень, у день, який був відведений для технічної підготовки. Нові вправи додавалися лише після повного засвоєння попередніх. Тож після експерименту ми отримали дані, які представлені в табл. 1, де наведено порівняльний аналіз змін результату у метанні спису серед юнаків та дівчат окремо.

Таблиця 1

Порівняльний аналіз змін результату у метанні спису

\begin{tabular}{|c|c|c|}
\hline $\begin{array}{c}\text { Етапи експери- } \\
\text { менту }\end{array}$ & $\begin{array}{c}\text { Результат } \\
\text { (юнаки) }\end{array}$ & $\begin{array}{c}\text { Результат } \\
\text { (дівчата) }\end{array}$ \\
\hline На початку, м & $53,83 \pm 9,33$ & $35,78 \pm 3,24$ \\
\hline Наприкінці, м & $56,73 \pm 9,36$ & $39,39 \pm 3,8$ \\
\hline Динаміка змін, \% & $5,52 \pm 2,36$ & $10,12 \pm 4,93$ \\
\hline
\end{tabular}

На рис. 3.2. можна прослідкувати розподіл коефіцієнтів у біомеханічних параметрів найкращої спроби спортсменів, які виконали тест наприкінці педагогічного експерименту.
Рис. 3 демонструє нам, що: спортсменка А покращила свій результат на $13,66 \%$, а також виконала норматив першого розряду; спортсменка В покращила свій результат на $13,16 \%$ і теж виконала норматив першого розряду; спортсменка $\mathrm{C}$ покращила свій результат на $3 \%$ і наблизилась до нормативу першого розряду; спортсменка D покращила свій результат на $10,66 \%$ та виконала норматив другого розряду; спортсмен Е покращив свій результат на $5,06 \%$; спортсмен $\mathrm{F}$ покращив свій результат на $8,30 \%$ та виконав норматив другого розряду; спортсмен $\mathrm{G}$ покращив свій результат на $6,11 \%$ і наблизився, але не виконав норматив другого розряду; спортсмен Н покращив свій результат на 2,60\% та наблизився до нормативу другого розряду;

Ми виявили, що в середньому група збільшила свої результати в метанні спису на 7,82 $4,34 \%$.

Табл. 2 та рис. 4 свідчать про те, що всі учні збільшили кількість вдалих спроб. Також можна зазначити, що змінився й темпоритм техніки метання спису. Він став більш рівномірним, без зайвих пауз. Учні стали більш стабільно тримати спису у руці таким чином, що він практично не змінює свого положення під час кидкових кроків. Також візуально більшість учнів ставить у правильне положення колінний суглоб після постановки лівої ноги на опору. Слід відмітити, що більшість учнів почали включати послідовно всі ланки тіла, а також починати розгін снаряду 3 двохопорного положення.

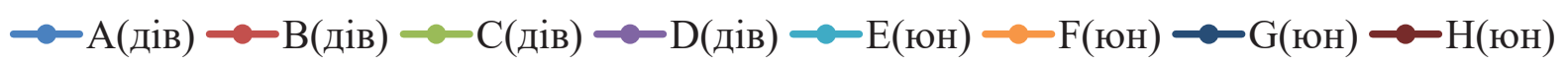

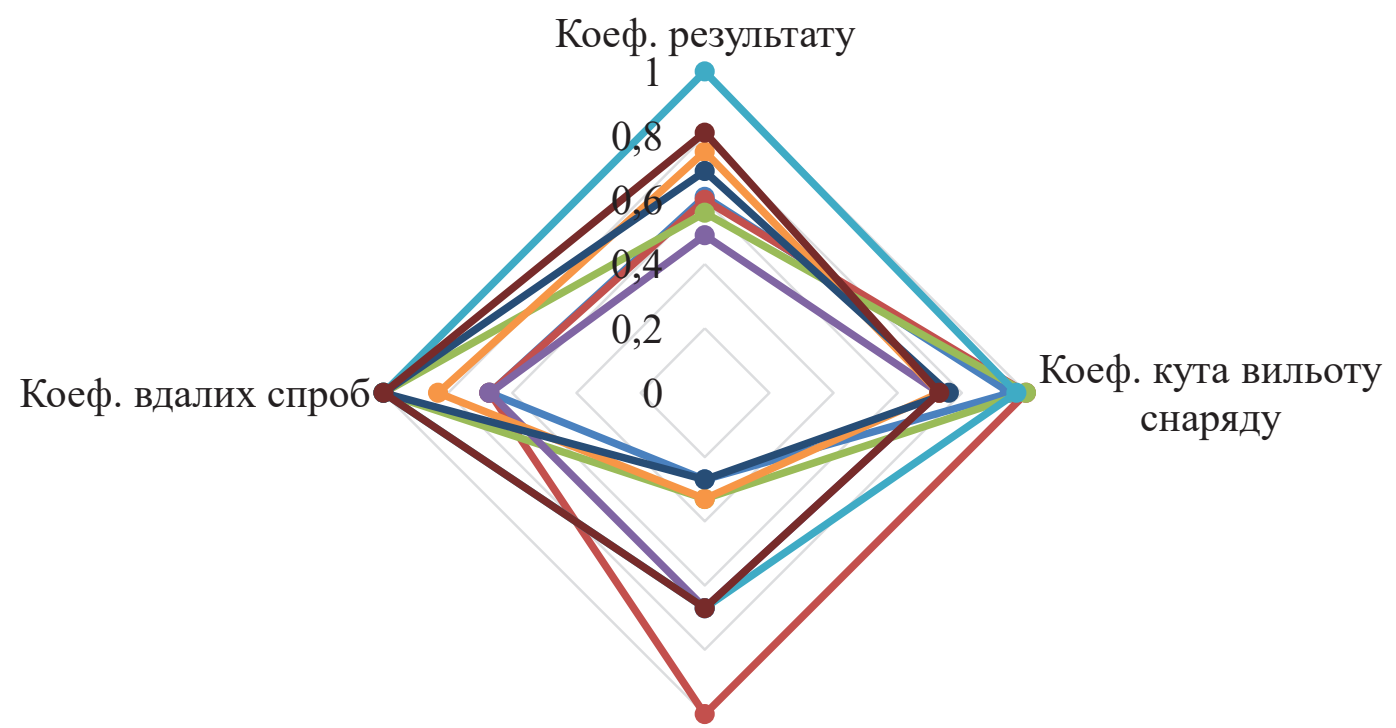

Коеф. відстані до

лінії після

гальмування

Рис. 2. Біомеханічні параметри метальників спису наприкінці педагогічного експерименту 


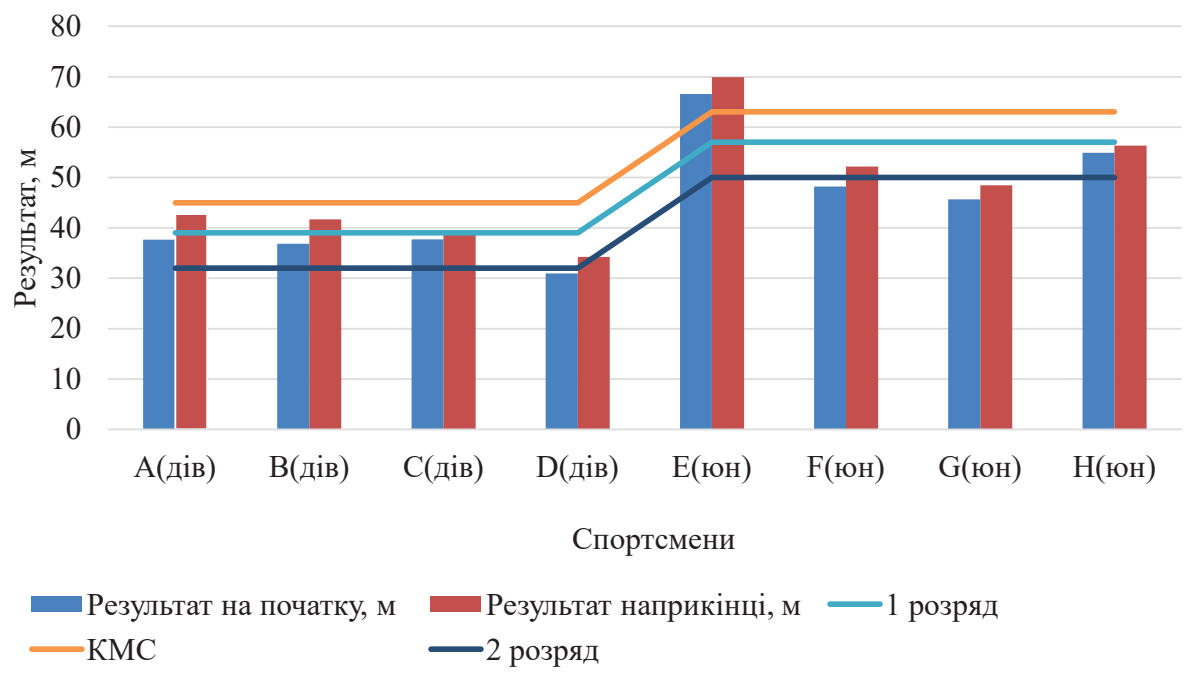

Рис. 3. Зміни у результаті у метанні спису та кваліфікаційні нормативи

Таблиця 2 відмінності між зв'язаними малими вибірками Порівняльний аналіз змін у кількості вдалих спроб у метанні спису

\begin{tabular}{|c|c|c|}
\hline $\begin{array}{c}\text { Етапи експери- } \\
\text { менту }\end{array}$ & $\begin{array}{c}\text { Кількість } \\
\text { спроб (юнаки) }\end{array}$ & $\begin{array}{c}\text { Кількість } \\
\text { спроб (дівчата) }\end{array}$ \\
\hline На початку, к-ть & $4 \pm 1,41$ & $3,5 \pm 1,73$ \\
\hline Наприкінці, к-ть & $5,1 \pm 0,5$ & $4 \pm 1$ \\
\hline Динаміка змін, \% & $29,17 \pm 21$ & $16,67 \pm 13,61$ \\
\hline
\end{tabular}

Для перевірки ефективності запропонованої програми вдосконалення рівня спеціальної технічної підготовленості метальників спису на етапі спеціалізованої підготовки було проведено статистичну обробку отриманих даних. На першому етапі обробки було встановлено, що вибірка даних за показниками асиметрії 1,95 (А) та ексцесу 3,52 (Е) $є$ близькою до нормального розподілення. На другому етапі було обрано для порівняльного аналізу зв'язаних вибірок непараметричний критерій Вілкоксону (T), оскільки він дозволяє оцінити (меньше 10) за рівнем якої-небудь ознаки, яка змінювалась кількісно. Він дорівнювався 0, у цьому випадку емпіричне значення $\mathrm{T}$ потрапляє у зону значимості: Темп $<$ Ткр $(0,01)$. Нульова гіпотеза приймається. Вона означає, що показники після педагогічного експерименту щодо впровадження запропонованої програми спеціальної технічної підготовленості метальників спису на етапі спеціалізованої підготовки перевищують значення показників до нього.

Отже, констатуємо, що відбулося статистично значуще зростання рівня спеціальної технічної підготовленості метальників спису на етапі спеціалізованої підготовки.

Висновки. Після закінчення запропонованої тренувальної програми ми довели іiі ефективність за допомогою статистичної обробки даних. Було констатовано статистично значуще зростання рівня спеціальної технічної підготов-

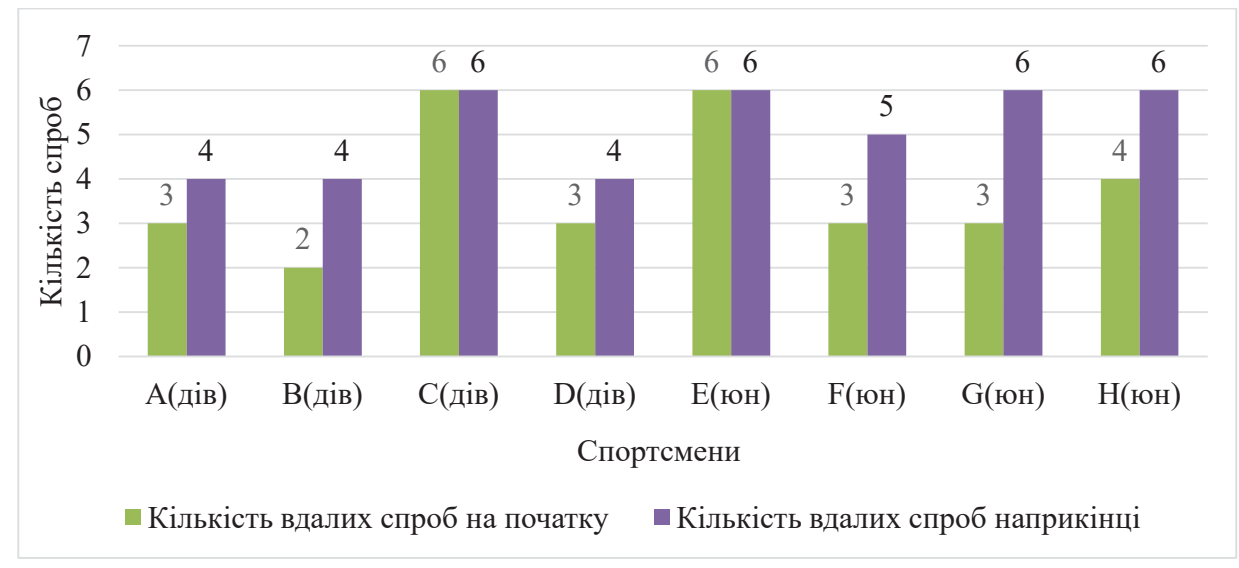

Рис. 4. Зміни у кількості вдалих проб 
леності метальників спису на етапі спеціалізованої підготовки. Результати контрольного тестування наприкінці педагогічного експерименту показали покращення результату в середньому на $7,82 \pm 4,34 \%$, а також поліпшення в деяких окремих біомеханічних параметрах техніки метання спису. Програма спеціальної технічної підготовки метальників спису потребує ретельного аналізу та корегування для впровадження у тренувальний процес. Проблема спеціальної технічної підготовки метальників спису на етапі спеціалізованої підготовки потребує поглибленого дослідження. Розробка програми тренувань $\epsilon$ різноманітною та багатогранною і підходить не для кожного спортсмена, тому під час розробки треба враховувати індивідуальні особливості стану в інших видах підготовленості метальників та не наражати їх на перетренованість, запобігати травмуванню.

\section{ЛІТЕРАТУРА}

1. Weineck J. Sportbiologie. Balingen : Spitta Verlag GmbH \& Co. KG, 2010. 1142 p.

2. Платонов В.Н. Адаптация в спорте. Киев : Здоров'я, 1988. 216 с.

3. Солодков А.С. Физиологические основы адаптации к физическим нагрузкам. Ленинград : ГДОИФК им. П.Ф. Лесгафта, 1988. 38 с.

4. Платонов В.Н. Система подготовки спортсменов в олимпийском спорте: общая теория и ее практические приложения. Москва : Советский спорт, 2005. 820 с.

5. Бобровник В.І., Совенко С.П., Колот А.В. Легка атлетика: Навчальна програма для дитячо-юнацьких спортивних шкіл, спеціалізованих дитячо-юнацьких спортивних шкіл олімпійського резерву, шкіл вищої спортивної майстерності та спеціалізованих навчальних закладів спортивного профілю. Київ : Логос, 2019. 192 с.

6. Курамшин Ю.Ф. Теория и методика физической культуры Москва : Советский спорт, 2010. 320 с.

7. Карпеев А.Г. Исследования техники метания копья и некоторые пути совершенствования технической подготовленности копьеметателей : автореф. дис. канд. пед. наук. ; Гос. ин-т физ. культуры. Омск, 1973. 17 с.

8. Ланка Я.Е. Биомеханические исследования работы правой ноги в финальной части метания копья. Междунар. научно-практ. конф. государств - участников СНГ по проблемам физической культуры и спорта : материалы Межнародной научно-практической конференции (Минск 27-28 мая 2010 г / редкол. М. Е. Корбинский (гл. ред) и др.) Минск : БГУФК, 2010. Ч. 2. С. 337-341.

9. Bartlett R. M. Theree-dimensional evaluation of the release parameters for javelin trowers of different skill levels / R. M. Bartlett, E. Muller, S. Lindinger, F. Brunner and C. Morris. Journal of Applied Biomechanics, 1996. Vol. 12. P. 58-72.

10. Mazzalitis V. Азбука метания копья (на латышнском языке). Riga : A/S Poligrafirsts, 1999. 180 p.

11. Morris C. The function of blocking in elite javelin throws A reevaluation. C Morris, R. Bartlett and E. Navarro. Of Human Movement Studies. 2001. Vol. 5. P. 175-190.

12. Jonath U., Krempel R., Haag E., Müller H.(1995). Leichtathletik 3 - Werfen und Mehrkampf. Hamburg : Rowohlt Taschenbuch Verlag gmbh, 1995. 688 p.

13. Врублевский Е.П. Научно-методичсекие основы инивидуализации тренировочного процесса спортсменок в скоростно-силовых видах лёгкой атлетики. Смоленск : СТАФКСТ, 2008. 340 с.

14. Дьячков В.М. Совершенствование технического мастерства спортсменов. Москва : Физкультура и спорт, 1972. $231 \mathrm{c}$.

15. Дмитрусенко О.3. Метание копья: формы и методы тренировки. Лёгкая атлетика. 1991. № 5. С. $15-18$.

16. Пурвин Э.В. Обусловленность спортивного результата в метаниях копья пространственными характеристиками техники метательниц. Актуальные вопросы биомеханики спорта. Смоленск, 1985. C. 103-105.

\section{REFERENCES}

1. Weineck J. Sportbiologie. Balingen: Spitta Verlag GmbH \& Co. KG, 2010. 1142 p.

2. Platonov V.N. Adaptatsiya v sporte [Adaptation in sports]. Kiev: Zdorov'ya, 1988. 216 p.

3. Solodkov A. S. Fiziologicheskie osnovyi adaptatsii k fizicheskim nagruzkam [Physiological basis of adaptation to physical activity]. L: GDOIFK im. P. F. Lesgafta, 1988. 38 p.

4. Platonov V. N. Sistema podgotovki sportsmenov v olimpiyskom sporte: obschaya teoriya i ee prakticheskie prilozheniya [The system of training athletes in the Olympic sport: general theory and its practical applications]. Moscow: Soviet sport, 2005. 820 p.

5. Bobrovnik V. I., Sovenko S. P., Kolot A. V. Legka atletika: Navchalna programa dlya dityacho-yunatskih sportivnih shkil, spetsializovanih dityacho-yunatskih sportivnih shkil olimpiyskogo rezervu, shkil vis- 
choyi sportivnoyi maysternosti ta spetsializovanih navchalnih zakladiv sportivnogo profilyu [Athletics: Curriculum for children and youth sports schools, specialized children and youth sports schools of the Olympic reserve, schools of higher sportsmanship and specialized educational institutions of sports profile]. K .: Logos, 2019. 192 p.

6. Kuramshin Yu. F. Teoriya i metodika fizicheckoy kulturyi [Theory and methodology of physical culture]. M .: Soviet sport, 2010.320 p.

7. Karpeev A. G. Issledovaniya tehniki metaniya kopya i nekotoryie puti sovershenstvovaniya tehnicheckoy podgotovlennosti kopemetateley: avtoref. dis. kand. ped. nauk [Research of the javelin throwing technique and some ways of improving the technical preparedness of javelin throwers: abstract of Ph.D. dis. Cand. ped. Sciences]. State in-t physical culture, Omsk, 1973. 17 p.

8. Lanka Ya. E. Biomehanicheskie issledovaniya rabotyi pravoy nogi v finalnoy chasti metaniya kopya [Biomechanical studies of the work of the right leg in the final part of the javelin throw / Ya. E. Lanka, AA Shalmanov. Int. scientific and practical. conf. of the CIS member states on the problems of physical culture and sports: materials of the International Scientific and Practical Conference (Minsk May 27-28, 2010 / editorial board M. E. Korbinsky (chief editor) and others]. Minsk: BSUFK, 2010. Part 2. P. 337-341.

9. Bartlett R. M. Theree-dimensional evaluation of the release parameters for javelin trowers of different skill levels / R. M. Bartlett, E. Muller, S. Lindinger, F. Brunner and C. Morris. Journal of Applied Biomechanics, 1996. Vol. 12. P. 58 - 72.

10. Mazzalitis V. Azbuka metaniya kopya ( na latyishnskom yazyike) [The alphabet of javelin throwing (in Latvian)]. Riga: A / S Poligrafirsts, 1999. 180 p.

11. Morris C. The function of blocking in elite javelin throws A reevaluation. C Morris, R. Bartlett and E. Navarro. Of Human Movement Studies, 2001. Vol. 5. P. 175-190.

12. Jonath U., Krempel R., Haag E., Müller H.(1995). Leichtathletik 3 - Werfen und Mehrkampf. Hamburg: Rowohlt Taschenbuch Verlag gmbh, 1995. 688 st.

13. Vrublevskiy E. P. Nauchno-metodichsekie osnovyi inividualizatsii trenirovochnogo protsessa sportsmenok v skorostno-silovyih vidah lyogkoy atletiki [Scientific and methodical bases of individualization of the training process of female athletes in speed-strength types of athletics]. Smolensk: STAFKST, 2008. 340 p.

14. Dyachkov V. M. Sovershenstvovanie tehnicheskogo masterstva sportsmenov [Improving the technical skills of athletes]. M: Physical culture and sport, 1972. $231 \mathrm{p}$.

15. Dmitrusenko O. Z. Metanie kopya: formyi i metodyi trenirovki [Javelin throw: forms and methods of training]. Athletics, 1991. No. 5. P. 15-18.

16. Purvin E. V. Obuslovlennost sportivnogo rezultata $v$ metaniyah kopya prostranstvennyimi harakteristikami tehniki metatelnits. Aktualnyie voprosyi biomehaniki sporta [Conditionality of the sports result in javelin throwing by the spatial characteristics of the throwers' technique. Topical issues of sports biomechanics]. Smolensk, 1985. P. 103-105. 